\title{
Introduction: the present and the future of tourism amidst COVID-19
}

\author{
Robin Nunkoo, Dogan Gursoy, Mehmet Sarışsık and Erhan Boğan
}

Around mid-December 2019, Wuhan, one of the most populous cities in China, experienced an outbreak of coronavirus (COVID-19) caused by the severe acute respiratory syndrome coronavirus 2 (Yang et al., 2020). The World Health Organization declared the outbreak as a public health emergency of international concern on January 30, 2020, and a pandemic on March 11, 2020. On December 15, 2020, the European Centre for Disease Prevention and Control (ECDP) reported 71503614 cases and 1612833 deaths worldwide. The negative impacts of COVID-19 are not only limited to the loss of human lives, but also include short- and long-term social, economic and political effects. The Organisation for Economic Co-operation and Development (OECD, 2020), for example, forecasts that a long-lasting and more intensive COVID-19 outbreak is likely to drop global growth to 1.5 percent in 2020 , which is half the projected rate of growth prior to the outbreak, with implications for international tourism. Similarly, the International Monetary Fund forecasts that the COVID-19 outbreak could cause a global recession that could be worse than the one triggered by the global financial crisis of 2008-09.

As an immediate response to the pandemic, several countries adopted non-pharmaceutical measures such as social distancing and lockdown involving closure of several public services, educational institutions and workplaces, and home isolation (Gössling et al., 2020; Gursoy and Chi, 2020). Travel restrictions immediately followed, with some countries closing their borders completely, others only partially. In April 2020, the International Air Travel Association estimated that nine out of ten people worldwide live in countries with travel restrictions: 99 countries suspended flights; 52 countries were closed to non-residents/nationals; 48 countries were closed to specific countries; 15 countries were open, but required health checks or quarantine; and only three countries had no travel restrictions.

As a direct consequence of the travel restrictions, the tourism and hospitality sector suffered a huge economic downturn as tourist arrivals worldwide fell drastically. The United Nations World Tourism Organization (UNWTO) estimates that international tourist arrivals declined by 70 percent in January-August 2020 compared to the same period of the previous year. This translates into a loss of US\$730 billion in export revenues from international tourism, more than eight times the loss in 2009 under the impact of the global economic crisis. The Asia-Pacific region saw the most dramatic decrease in tourist arrivals, followed by Africa and the Middle East. It comes as a no surprise that the socio-economic implications of COVID-19 have come under close scrutiny by researchers. There has been an upsurge of studies on the socio-economic implications of COVID-19 (Atalan, 2020; Danielli et al., 2021; Gautam and Lens, 2020). Tourism researchers have also engaged in similar discussions, providing scholars with a good understanding of the economic implications of pandemics on the tourism and hospitality sector (Gössling et al., 2020; Gursoy and Chi, 2020; Higgins-Desbiolles, 2021; Yeh, 2020). 
Against this background, this volume brings together 27 chapters that discuss the impacts of COVID-19 on the global tourism and hospitality sector. The contributors approach the topic from an economic, sociological and psychological perspective, thus providing readers with a comprehensive understanding of the implications of the pandemic for tourism. Oğuz Türkay and Burak Atasoy further the discussions on the economic impacts of the pandemic in the opening chapter of the volume (Chapter 1). The contributors delve into the theoretical perspectives on crisis, and discuss the various crises that have impacted the tourism industry. The chapter then presents the various socio-economic effects of crisis on the tourism and related sectors. The contributors conclude by reviewing the various strategies that countries have adopted to manage major pandemics. In Chapter 2, Erhan Boğan and Caner Çalışkan review the most influential pandemics and evaluate their impacts on the tourism sector. The chapter concludes by emphasizing that pandemics should be considered as an on-going aspect of human lives.

Mehmet Sarışık and Sevim Usta analyze the effects of COVID-19 on the global economy in Chapter 3. In the opening section of the chapter, the contributors discuss the general problems and effects of COVID-19. The chapter then delves into the developments in the field of health since the emergence of COVID-19. Then, the disease's effects on human life are emphasized by the contributors. In the following chapter (Chapter 4), Gözdegül Başer and Rüya Ehtiyar adopt a micro perspective on the consequences of COVID-19, focusing on its effects on a hotel's physical environment from the perspectives of employees and hotel guests. The contributors explain that the hotel required a certification program to operate in the context of COVID-19. This has meant that the physical environment of the hotel has been reorganized in accordance with the regulations of the certificate. The contributors effectively make use of visuals to support their arguments. The chapter then delves into the positive and negative changes in the hotel's physical environment as a result of the new certification and their implications for employees and guests. The contributors conclude their chapter by making recommendations that improve the experience of both employees and guests.

The COVID-19 pandemic requires that tourism and hospitality organizations rethink their marketing and promotion strategies (Jiang and Wen, 2020; Kock et al., 2020; Sánchez-Teba et al., 2020; Yeh, 2020). In Chapter 5, Şevki Ulema and Süleyman Akkaşoğlu discuss the implications of COVID-19 on marketing policies and practices. The contributors argue that while travel motivators such as the natural environment and the variety of services of a destination remain important determinants of tourism demand, as a result of COVID-19 the number of cases and death in a destination and the hygiene measures are additional considerations that have to be taken into account in marketing a destination's product. Engin Üngüren and Caner Güçlü conceptualize the impacts of COVID-19 from a sociological perspective in Chapter 6. In the opening paragraphs, Üngüren and Güçlü review the travel scenario for 2020 amidst COVID-19. The contributors then discuss the various sociological consequences of the pandemic, focusing on xenophobia and tourist hostility, tourist behavior, tourism employment, destination image and host perceptions.

Hugues Séraphin adopts a rather unique perspective in Chapter 7 to evaluate the impact of COVID-19, discussing the implications of the pandemic for children's perceptions of destinations. Hugues argues that there is still a dearth of research on children in the tourism industry, and there is also room for improvement in terms of research methods. The chapter suggests that the impacts of COVID-19 on the tourism industry might also be dual, reflecting the Janus-faced character of the industry. Pandemics such as COVID-19 have important implica- 
tions for tourist behavior (Chua et al., 2021; Kock et al., 2020; Wachyuni and Kusumaningrum, 2020). Volkan Genc and Seray Gülertekın Genc explore this topic in Chapter 8. In this chapter the contributors discuss the implications of COVID-19 for tourists' psychology and their purchasing behavior. The opening paragraphs of the chapter present theoretical perspectives for understanding tourist psychology and fear during crisis, with particular reference to the COVID-19 pandemic. The contributors then delve into the implications of the pandemic for travelers' purchase behaviors, focusing on the short-term, medium-term and long-term effects.

In Chapter 9, Mehmet Emin Baynazoğlu and Boban Melovic analyze the effects of COVID-19 on tourism investment, a topic on which academic discourses are limited. In the opening paragraphs of the chapter, the contributors present an overview of the current situation of world tourism amidst COVID-19. They then discuss the effects of COVID-19 on tourism investment, focusing on the current and future impacts. The chapter concludes by providing recommendations to mitigate the effects of COVID-19 on tourism and to expedite the tourism recovery process. Gamze Özoğul and Günseli Güçlütürk Baran further the debates in Chapter 10 , focusing on the impacts of COVID-19 on tourism management. In the opening sections of the chapter, the contributors use key statistics to argue the global implications of COVID-19 for the tourism sector and hospitality sector. The discussion then delves into different hotel management practices that have been implemented to deal with the pandemic. Özoğul and Baran then discuss the implications of COVID-19 for the food and beverage sector and the transport sector, before concluding with some strategies needed for destination recovery. The COVID-19 pandemic has implications for destination branding (Rossolatos, 2020). In Chapter 11, Aydın Yılmazer and Merve Işkın present strategies for developing a destination brand and image that can stimulate the desire of tourists to travel to destinations after COVID-19. First, the contributors discuss the approach to brand and the destination branding process. The concept of destination image is then explained, following which the contributors explain the impact of COVID-19 on destination brand image. The chapter proposes a post-COVID-19 destination brand strategy.

The impact of pandemics such as COVID-19 on tourism demand is well documented in the literature (Haryanto, 2020; Kuo et al., 2008; Kuo et al., 2009; Polyzos et al., 2020; Yang et al., 2020). In Chapter 12, Şenol Çavuş and Veli Ceylan discuss the effects of COVID-19 on tourism demand. The chapter starts with an overview of the decline of world tourist arrivals as a result of COVID-19, focusing on a regional analysis. The contributors then make a comparative study of the effects of COVID-19 on travel demand compared to other pandemics, before discussing the travel scenarios for 2020. The effects of COVID-19 on tourism education are discussed by Cleopas Njerekai in Chapter 13. After discussing the implications of the pandemic for tourism education in the opening paragraphs of the chapter, Njerekai discusses the strategic responses of education institutions to COVID-19. The chapter then delves into various contingency measures that the author recommends in the event of future pandemics.

In a similar vein, Serkan Şengül and Burak Eryılmaz investigate the impacts of COVID-19 on the tourism workforce in Chapter 14. The contributors use key statistics to support their arguments on the implications of the pandemic for tourism employment. The chapter presents the top 15 countries where the pandemic has had the most dramatic impact on skilled labor. Furthering the debate on this theme, Gülçin Özbay and Elif Kaymaz discuss the effects of COVID-19 on tourism employees' psychology in Chapter 15. The contributors argue that the uncertain environment, coupled with decreases in demand as a result of the COVID-19 pandemic, has led to job losses, economic anxiety, and a range of psychological problems for 
those affected such as decreasing motivation and energy level, feelings of hopelessness and helplessness, and loss of appetite, amongst others. The contributors then discuss the various fears and anxieties of tourism employees arising from the loss of jobs and the risks of transmission and contagion. In Chapter 16, Abdurrahman Benli and Özgür Topkaya discuss how the COVID-19 pandemic changed the supply chain management strategies of hotels, focusing on travel companies and human resource decisions. The contributors argue that travel agents, both online and brick and mortar, have been the main source of the customer base for international hotels during COVID-19.

In Chapter 17, Abhijeet Shirsat and Erik Luvaas discuss the effects of COVID-19 in California. In the opening discussion, the contributors present the context of COVID-19 in the destination before emphasizing the effects of the pandemic on the Golden State, reviewing the different sectors that were severely impacted. Job insecurity, policy change, well-being, economic impacts and public resistance are some of the points of discussion of the chapter. Zameelah Khan Jaffur and Boopen Seetanah investigate the impacts of COVID-19 in small island developing states in Chapter 18. The contributors provide valuable COVID-19 and tourism statistics for the sample of islands investigated. Their findings indicate that the COVID-19 pandemic has a statistically significant and negative effect on each of the selected islands' tourism markets, with the least effect on Bahamas and the greatest on Hong Kong. Güliz Coşkun analyzes social distancing and the sustainability of international events in Chapter 19. Güliz presents a typology of events, before delving into the impacts of international events and festivals. The discussion then focuses on the impact of COVID-19 on events and festivals.

The effects of COVID-19 on the food and beverage sector are discussed by Mehmet Sarışı and Mustafa İnanç Kapucuoğlu in Chapter 20. In the opening paragraphs of the chapter, the contributors exemplify the relationship between COVID-19 and the structure of food service, before discussing the influence of the pandemic on food contamination, and the implications for the food and beverage sector. In Chapter 21, Sheereen Fauzel discusses crisis management in the Mauritian tourism industry, a destination that has been hit not only by the COVID-19 pandemic, but also by the MV Wakashio oil spill. While COVID-19 has had devastating impacts on the tourism sector, Sheereen argues, the Wakashio oil spill may well affect this sector given that the image of the island is at stake and the pollution may result in tourists seeking other destinations than Mauritius. The discussion suggests that to reduce the impact of these crises on the industry, adequate disaster management strategies are required. Ceren Miral Çavdırlı and Özge Adan Gök further the discussion on crisis management in the tourism sector in Chapter 22. The contributors argue that although considerable research has dealt with crisis management, studies on the COVID-19 pandemic and its effects on tourism organizations are limited. The chapter fills this gap by providing deep understanding of the pandemic and the action plans taken by the management of the organizations.

Laurence Chalip, B. Christine Green, Minkyung Park, David Kanters and Michael A. Kanters investigate the reactions of parents to cancellation of elite youth travel sport events as a result of the COVID-19 pandemic, in Chapter 23. Drawing their conclusions from a survey of athletes' parents, the contributors find that the majority wanted their child to return to sport after the pandemic. Many worried that their child would lose interest in their sport; the children would be engaged in other activities on which they could focus instead. On average, parents reported that they and their child each experienced social loss from sports' shutdown, and many worried that their child would lose interest in their sport. The length of time their 
child had played the sport, and the parent's sense of personal social loss, positively predicted the strength of their desire for the child to return to sport; while greater fears about the safety of returning reduced their desire for the child to return to sport. In Chapter 24, Rinzing Lama and Debagni Sarkhel discuss the impacts of COVID-19 on tourism stakeholders in the Asian tourism markets. The chapter critically reviews the COVID-19 pandemic in four Asian economies, and concludes with some recommendations for the tourism recovery process in those destinations. Mustafa Kenan Erkan and Ümit Şengel investigate the effect of COVID-19 on financial practices in the hospitality sector in Chapter 25. The contributors argue that COVID-19 has had effects on the hospitality industry's financial measures such as liquidity, low profit margin, borrowing, cash flow, high interest rates, high fixed expenses and payments. Furthering this debate, Feridun Duman and Şenol Çavuş discuss the effect of COVID-19 on tourism revenues in Chapter 26, concluding that international tourism revenues decreased by up to 20 percent across the world in the first quarter of 2020. In the final chapter (Chapter 27), Derya Demirdelen Alrawadieh maps government response to the COVID-19 pandemic and discusses its implications for the hospitality and tourism industry in Turkey.

We, as editors of this book, acknowledge the fact that we may have left out some critical topics and/or concepts. For the sake of simplicity and functionality we have focused on the topics that are most critical for hospitality and tourism researchers and practitioners. Thus, the list of topics included in this book is not complete or exhaustive in its coverage of COVID-19 issues in hospitality and tourism. For this, we apologize. Our goal is simply to provide a list of the most critical COVID-19 topics in hospitality and tourism in one place in order to create a credible source of information that today's and future researchers and practitioners could use as a point of departure for their research initiatives and business endeavors.

The contributors to this book have spent countless hours on providing in-depth coverage of each conceptual and practical topic, so that each chapter can serve as a trusted source of reference that can provide essential knowledge and references on the respective topic for academics and practitioners. We would like to express our sincere gratitude and thanks to all the contributors who graciously volunteered their time and effort to put this amazing book together.

\section{REFERENCES}

Atalan, A. (2020). Is the lockdown important to prevent the COVID-19 pandemic? Effects on psychology, environment and economy-perspective. Annals of Medicine and Surgery, 56, 38-42.

Chua, B.L., Al-Ansi, A., Lee, M.J., \& Han, H. (2021). Tourists' outbound travel behavior in the aftermath of the COVID-19: role of corporate social responsibility, response effort, and health prevention. Journal of Sustainable Tourism, 29(6), 879-906.

Danielli, S., Patria, R., Donnelly, P., Ashrafian, H., \& Darzi, A. (2021). Economic interventions to ameliorate the impact of COVID-19 on the economy and health: an international comparison. Journal of Public Health, 43(1), 42-46.

Gautam, S., \& Hens, L. (2020). COVID-19: impact by and on the environment, health and economy. Environment, Development and Sustainability, 22, 4953-4954.

Gössling, S., Scott, D., \& Hall, C.M. (2020). Pandemics, tourism and global change: a rapid assessment of COVID-19. Journal of Sustainable Tourism, 29(1), 1-20.

Gursoy, D., \& Chi, C.G. (2020). Effects of COVID-19 pandemic on hospitality industry: review of the current situations and a research agenda. Journal of Hospitality Marketing and Management, 29(5), 527-529.

Haryanto, T. (2020). Covid-19 pandemic and international tourism demand. Journal of Developing Economies, 5(1), 1-5. 
Higgins-Desbiolles, F. (2021). The "war over tourism": challenges to sustainable tourism in the tourism academy after COVID-19. Journal of Sustainable Tourism, 29(4), 551-569.

Jiang, Y., \& Wen, J. (2020). Effects of COVID-19 on hotel marketing and management: a perspective article. International Journal of Contemporary Hospitality Management, 32(8), 2563-2573.

Kock, F., Nørfelt, A., Josiassen, A., Assaf, A.G., \& Tsionas, M.G. (2020). Understanding the COVID-19 tourist psyche: the evolutionary tourism paradigm. Annals of Tourism Research, 85, 103053.

Kuo, H.I., Chang, C.L., Huang, B.W., Chen, C.C., \& McAleer, M. (2009). Estimating the impact of avian flu on international tourism demand using panel data. Tourism Economics, 15(3), 501-511.

Kuo, H.I., Chen, C.C., Tseng, W.C., Ju, L.F., \& Huang, B.W. (2008). Assessing impacts of SARS and Avian Flu on international tourism demand to Asia. Tourism Management, 29(5), 917-928.

OECD (2020). Tourism Policy Responses to the Coronavirus. Retrieved December 21, 2020, from https://www.oecd.org/coronavirus/policy-responses/tourism-policy-responses-to-the-coronavirus -covid-19-6466aa20/.

Polyzos, S., Samitas, A., \& Spyridou, A.E. (2020). Tourism demand and the COVID-19 pandemic: an LSTM approach. Tourism Recreation Research, 1-13. DOI: https://doi.org/10.1080/02508281.2020 .1777053 .

Rossolatos, G. (2020). A brand storytelling approach to Covid-19's terrorealization: cartographing the narrative space of a global pandemic. Journal of Destination Marketing and Management, 18, 100484.

Sánchez-Teba, E.M., García-Mestanza, J., \& Rodríguez-Fernández, M. (2020). The application of the inbound marketing strategy on Costa del Sol Planning and Tourism Board: lessons for post-COVID-19 revival. Sustainability, 12(23), 9926.

Wachyuni, S.S., \& Kusumaningrum, D.A. (2020). The effect of COVID-19 pandemic: how are the future tourist behavior? Journal of Education, Society and Behavioural Science, 67-76. DOI: 10.9734/ jesbs/2020/v33i430219.

Yang, Y., Zhang, H., \& Chen, X. (2020). Coronavirus pandemic and tourism: dynamic stochastic general equilibrium modeling of infectious disease outbreak. Annals of Tourism Research, 83, 102913.

Yeh, S.S. (2020). Tourism recovery strategy against COVID-19 pandemic. Tourism Recreation Research, 1-7. DOI: https://doi.org/10.1080/02508281.2020.1805933. 